\title{
Clinical significance and biological roles of cyclins in gastric cancer
}

This article was published in the following Dove Press journal:

OncoTargets and Therapy

\author{
Hai-Ping Zhang' \\ Shu-Yu Li ${ }^{2}$ \\ Jian-Ping Wang' \\ Jun Lin'
}

'Department of Gastroenterology, Zhongnan Hospital of Wuhan University, Wuhan City, Hubei Province 43007I, China; ${ }^{2}$ Department of Gastroenterology, Zhongshan Hospital of Hubei Province, Wuhan City, Hubei Province 43007I, China

Correspondence: Jun Lin Department of Gastroenterology, Zhongnan Hospital of Wuhan University, 165 Donghu Road, Wuchang District, Wuhan City, Hubei Province 43007I, China

Tel +86I397 II5 6723

Email linjun5478@I63.com
Background and aim: Cyclins have been reported to be overexpressed with poor prognosis in several human cancers. However, limited numbers of studies evaluated the expressions and prognostic roles of cyclins in gastric cancer (GC). We aim to evaluate the expressions and prognostic roles of cyclins. Also, further efforts were made to explore biological function of the differentially expressed cyclins.

Methods: Cyclins expressions were analyzed by Oncomine and The Cancer Genome Atlas datasets, and the prognostic roles of cyclins in GC patients were investigated by the Kaplan-Meier Plotter database. Then, a comprehensive PubMed literature search was performed to identify expression and prognosis of cyclins in GC. Biological functions of the differentially expressed cyclins were explored through Enrich R platform, and KEGG and transcription factor were analyzed.

Results: The expression levels of CCNA2 (cyclin A2), CCNB1 (cyclin B1), CCNB2 (cyclin B2), and CCNE1 (cyclin E1) mRNAs were identified to be significantly higher in GC tissues than in normal tissues in both Oncomine and The Cancer Genome Atlas datasets. High expressions of CCNA2, CCNB1, and CCNB2 mRNAs were identified to be related with poor overall survival in Kaplan-Meier Plotter dataset. Evidence from clinical studies showed that CCNB1 was related with overall survival in GC patients. Cyclins were associated with several biological pathways, including cell cycle, p53 signaling pathway, FoxO signaling pathway, viral carcinogenesis, and AMPK signaling pathway. Enrichment analysis also showed that cyclins interacted with some certain transcription factors, such as FOXM1, SIN3A, NFYA, and E2F4.

Conclusion: Based on our results, high expressions of cyclins were related with poor prognosis in GC patients. The above information might be useful for better understanding the clinical and biological roles of cyclins mRNA and guiding individualized treatments for GC patients.

Keywords: gastric cancer, cyclins, expression, prognosis, biological function

\section{Introduction}

Gastric cancer (GC) is estimated to be one of the most leading causes of all deaths worldwide. ${ }^{1}$ Every year, nearly one million new cases occur and around 7,00,000 people die of GC. ${ }^{2}$ Although there is a decrease in incidence in the recent years, patients with GC still suffer from a poor prognosis, which brought great burden to global health and economy. ${ }^{3,4}$ Tumor resection or lymphadenectomy is one of the main treatments for advanced GC. ${ }^{5}$ However, surgical treatment alone is associated with high recurrence rates. ${ }^{6,7}$ Therefore, identification of the molecular mechanism during GC pathogenesis, as well as identification of potential prognostic biomarkers and drug targets is still needed.

Cyclins, including cyclin A, B, D, and E, act as key controlling elements of the eukaryotic cell cycle. ${ }^{8}$ Considerable efforts have been expended in order to understand 
the potential biological mechanism and clinical significance of cyclins in human cancers. ${ }^{8-11}$ Many studies demonstrated that the expressions of cyclins were overexpressed in human cancers and correlated with poor clinical outcomes in lung cancer, ${ }^{12-17}$ breast cancer, ${ }^{18-28}$ and ovarian cancer. ${ }^{29-34}$ However, limited numbers of studies evaluated the expressions and prognostic roles of cyclins in GC patients, ${ }^{35-37}$ and additional efforts are still needed to explore their biological function.

Oncomine (http://www.oncomine.org), ${ }^{38}$ a cancer microarray database and web-based data mining platform, could automatically compute differential expression profiles between cancer and normal tissues for a gene of interest. Kaplan-Meier Plotter (KM Plotter; http://kmplot.com/ analysis/) is capable of assessing the effect of 54,675 genes on survival using 1,065 GC samples. ${ }^{39}$ In the present study, we aim to evaluate the expressions and prognostic roles of different cyclins in GC patients through the above two databases. For further biological function analysis of cyclins, enrichment analysis was performed by Enrich platform. ${ }^{40}$ In this study, we aim to study the clinical significance and biological mechanism of cyclins during GC pathogenesis through bioinformatics methods.

\section{Materials and methods \\ Oncomine database analysis}

Oncomine (http://www.oncomine.org), which contains 715 datasets and 86,733 samples, was utilized to examine the cyclins mRNA expressions between GC and normal tissues. ${ }^{38}$ The thresholds were restricted to the following: $P$-value: 0.05 ; fold change: 2.0 ; gene rank: all; and data type: mRNA. We performed comparisons by cancer vs normal analysis. Fold change, $P$-value, gene rank, and sample sizes were obtained from studies that showed statistically significant differences.

Then, the GSE13861, GSE27342, GSE13911, and GSE19826 datasets were employed from Oncomine database, and the raw data of cyclins expressions were downloaded. After normalization, a meta-analysis was conducted by Review Manager. The standardized mean difference was calculated. $P$-value $<0.05$ was considered to be statistically significant. Heterogeneity among studies was evaluated by the Cochran's $Q$ test and $I^{2}$ statistic. The $P$-value for Cochran's $Q$ test $<0.1$ or $I^{2}>50 \%$ was considered to be heterogeneous. Pooled analysis was applied with a fixed-effects model if no heterogeneity was detected. Random-effects model was applied if any heterogeneity existed.

For validation, the expressions of cyclins for GC patients in The Cancer Genome Atlas (TCGA; https://cancergenome. nih.gov/) dataset were analyzed. The TCGA GC data included 32 normal and 375 GC samples.

\section{KM Plotter database analysis}

KM Plotter (http://kmplot.com/analysis/) is capable of assessing the effect of 54,675 genes on survival using 10,461 cancer samples. ${ }^{39}$ Currently, it contains 5,143 breast, 1,618 ovarian, 2,437 lung, and 1,065 GC patients with a mean follow-up of 69/40/49/33 months, respectively. The prognostic roles of cyclins in GC were assessed by KM Plotter. GC patients were divided into high- and low-expression groups by the median values of mRNA expression. The overall survival (OS) of GC patients was measured by calculating logrank $P$-value and hazard ratio (HR) with $95 \%$ CI. Number of cases, HRs with 95\% CIs, and $P$-values were extracted from the KM Plotter webpage. In this study, "array quality control" was selected, and "exclude biased arrays" without follow-up. The GSE14210, GSE15459, GSE22377, GSE29272, and GSE51105 datasets were employed for pooled survival analysis from KM Plotter database.

\section{Literature search of expression and prognosis of cyclins in GC}

A comprehensive PubMed literature search was performed to identify expression and prognosis of cyclins in GC. The following keywords were used: "gastric cancer", "stomach adenocarcinoma", "gastric adenocarcinoma", "survival", "prognosis", "gene expression", "CCNA2", "CCNB1", "CCNB2", and "CCNE1". The prognosis roles of cyclins were reviewed by comprehensive literature search.

\section{Enrichment analysis of cyclins}

In order to obtain additional biological information of the differentially expressed cyclins, a comprehensive functional gene set analysis was performed using the EnrichR platform..$^{40}$ EnrichR platform includes 69 gene-set libraries, such as KEGG, WikiPathways, Gene Ontology, and transcription factor (TF). $P$-value and $Z$-score were calculated for enrichment analysis, and protein-protein interaction (PPI) network was constructed. The $P$-value is computed using a standard statistical method used by most enrichment analysis tools - Fisher's exact test or the hypergeometric test. The $Z$-score is computed using a modification to Fisher's exact test in which an $Z$-score was computed for deviation from an expected rank. For multiple hypotheses, BenjaminiHochberg $(\mathrm{BH})$ procedure was used. 


\section{Results}

\section{Cyclins mRNA expression in GC patients}

Using Oncomine analysis, we investigated mRNA levels of cyclins in GC patients. The differentially expressed cyclins in four datasets ${ }^{41-44}$ are shown in Table 1. The mRNA expression levels of CCNA2, CCNB1, CCNB2, CCND2, and CCNE1 were significantly higher in GC than in normal tissues in each single dataset. CCNB1 and CCNE1 mRNA expressions were also significantly higher in gastric diffuse adenocarcinoma and gastric intestinal adenocarcinoma, respectively. The pooled analysis, by comparing different studies in Oncomine datasets, showed that CCNA2, CCNB1, CCNB2, and CCNE1 were significantly higher in GC than in normal tissues (Figure 1).

The expressions of cyclins were analyzed in TCGA $\mathrm{GC}$ dataset for validation. The mRNA expression levels of CCNA2, CCNB1, CCNB2, and CCNE1 were significantly higher in GC than in normal tissues, while CCND2 did not show the significance (Figure 2). The receiver operating characteristic (ROC) curves of CCNA2, CCNB1, CCNB2, and CCNE1 were constructed for GC diagnosis (Figure S1). Besides, CCNB1 and CCNE1 mRNA expressions were also significantly higher in diffuse gastric adenocarcinoma and gastric intestinal type adenocarcinoma, respectively (Figure 3). Also, the ROC curves of CCNB1 and CCNE1 were constructed for GC Lauren subtype classification (Figure S2).

In summary, CCNA2, CCNB1, CCNB2, and CCNE1 were identified to be differentially expressed in $\mathrm{GC}$ tissues in both Oncomine and TCGA datasets. Furthermore, CCNB1 and CCNE1 expressions were also differentially expressed in GC Lauren subtype, which indicated that CCNB1 and CCNE1 might be helpful to classify GC Lauren subtypes.

\section{Prognostic role of cyclins mRNA in GC patients}

The prognostic roles of differentially expressed cyclins in GC were assessed by KM Plotter. Survival curves were plotted for GC patients. High expressions of CCNA2

Table I The differentially expressed cyclins mRNA in GC

\begin{tabular}{|c|c|c|c|c|c|}
\hline Symbol & Dataset & $\begin{array}{l}\text { Sample } \\
\text { (tumor/normal) }\end{array}$ & $\begin{array}{l}\text { Fold } \\
\text { change }\end{array}$ & $P$-value & $\begin{array}{l}\text { Gene } \\
\text { rank }\end{array}$ \\
\hline \multicolumn{6}{|c|}{ GC vs normal } \\
\hline CCNA2 & Cui et $\mathrm{al}^{41}$ & $80 / 80$ & 2.204 & $3.02 \mathrm{E}-05$ & 513 \\
\hline \multirow[t]{2}{*}{ CCNBI } & Cui et $\mathrm{al}^{41}$ & $80 / 80$ & 2.006 & $2.13 \mathrm{E}-05$ & 484 \\
\hline & Wang et $\mathrm{a}^{42}$ & $12 / 15$ & 2.251 & $1.20 \mathrm{E}-02$ & 3,624 \\
\hline \multirow[t]{2}{*}{ CCNB2 } & Cui et $\mathrm{al}^{4 \mathrm{l}}$ & $80 / 80$ & 3.111 & $6.38 \mathrm{E}-04$ & 1,009 \\
\hline & Wang et $\mathrm{a}^{42}$ & $12 / 15$ & 2.555 & $9.00 \mathrm{E}-03$ & 3,222 \\
\hline CCND2 & Wang et $\mathrm{a}^{42}$ & $12 / 15$ & 2.449 & 2.27E-04 & 489 \\
\hline \multirow[t]{2}{*}{ CCNEI } & Cui et $\mathrm{al}^{41}$ & $80 / 80$ & 2.232 & $2.00 \mathrm{E}-03$ & 1,385 \\
\hline & Wang et $\mathrm{a}^{42}$ & $12 / 15$ & 3.099 & $7.00 \mathrm{E}-03$ & 2,918 \\
\hline \multicolumn{6}{|c|}{ Gastric intestinal type adenocarcinoma vs normal } \\
\hline CCNA2 & D'Errico et $\mathrm{al}^{43}$ & $26 / 31$ & 2.898 & $1.03 \mathrm{E}-10$ & 445 \\
\hline CCNBI & D'Errico et al ${ }^{43}$ & $26 / 31$ & 3.126 & $1.58 \mathrm{E}-10$ & 488 \\
\hline CCNB2 & D'Errico et $\mathrm{al}^{43}$ & $26 / 31$ & 3.087 & $2.66 \mathrm{E}-10$ & 551 \\
\hline CCND2 & D'Errico et $\mathrm{al}^{43}$ & $26 / 31$ & 4.016 & 2.17E-05 & 3,409 \\
\hline \multirow[t]{2}{*}{ CCNEI } & D'Errico et al ${ }^{43}$ & $26 / 31$ & 3.598 & I.7IE-08 & $\mathrm{I}, 186$ \\
\hline & Cho et $\mathrm{al}^{44}$ & $20 / 19$ & 2.059 & 7.IIE-04 & 1,013 \\
\hline \multicolumn{6}{|c|}{ Diffuse gastric adenocarcinoma vs normal } \\
\hline CCNBI & D'Errico et al ${ }^{43}$ & $6 / 31$ & 2.187 & $8.00 \mathrm{E}-03$ & 2,390 \\
\hline CCNEI & Cho et $\mathrm{a}^{44}$ & $31 / 19$ & 2.594 & $3.35 \mathrm{E}-06$ & 421 \\
\hline \multicolumn{6}{|c|}{ Gastric mixed adenocarcinoma vs normal } \\
\hline \multirow[t]{2}{*}{ CCNA2 } & D'Errico et al ${ }^{43}$ & $4 / 31$ & 2.261 & $6.00 \mathrm{E}-03$ & 3,126 \\
\hline & Cho et $\mathrm{al}^{44}$ & $10 / 19$ & 2.059 & $6.20 \mathrm{E}-04$ & 920 \\
\hline \multirow[t]{2}{*}{ CCNBI } & $D^{\prime}$ Errico et $\mathrm{al}^{43}$ & $4 / 31$ & 3.294 & $8.00 \mathrm{E}-03$ & 3,492 \\
\hline & Cho et $\mathrm{al}^{44}$ & $10 / 19$ & 2.406 & I.I2E-04 & 414 \\
\hline CCNB2 & D'Errico et $\mathrm{al}^{43}$ & $4 / 31$ & 2.168 & $1.20 \mathrm{E}-02$ & 4,049 \\
\hline \multirow[t]{2}{*}{ CCND2 } & D'Errico et al ${ }^{43}$ & $4 / 31$ & 3.300 & $8.00 \mathrm{E}-03$ & 3,462 \\
\hline & Cho et $\mathrm{al}^{44}$ & $10 / 19$ & 2.459 & $2.00 \mathrm{E}-03$ & 1,423 \\
\hline CCNEI & D'Errico et $\mathrm{al}^{43}$ & $4 / 31$ & 2.417 & I.40E-02 & 4,360 \\
\hline \multicolumn{6}{|c|}{ Gastric adenocarcinoma vs normal } \\
\hline CCNBI & Cho et $\mathrm{al}^{44}$ & $4 / 19$ & 2.516 & $2.40 \mathrm{E}-02$ & 1,555 \\
\hline
\end{tabular}

Note: Data were extracted from the Oncomine database. Abbreviation: GC, gastric cancer. 


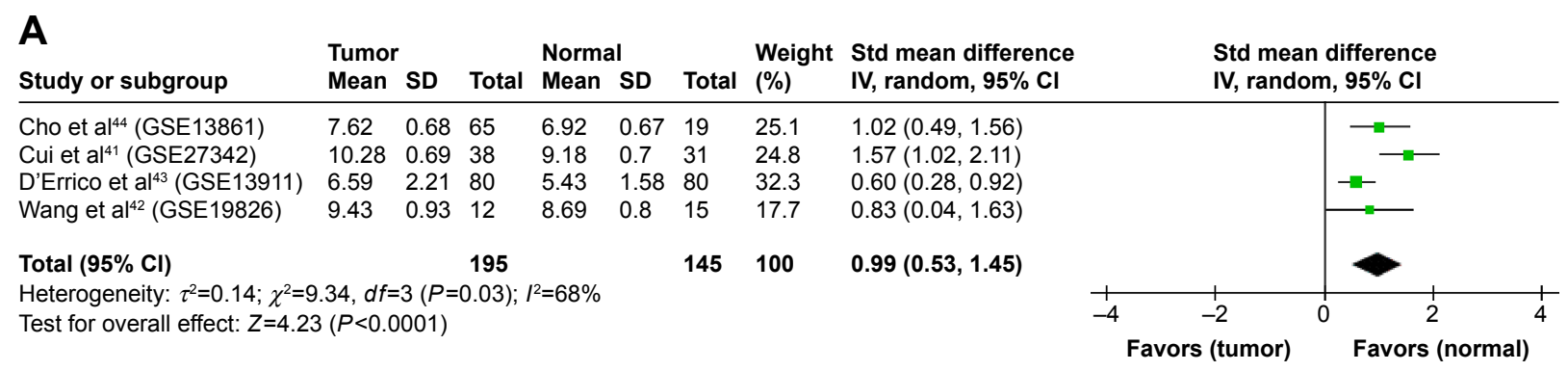

B

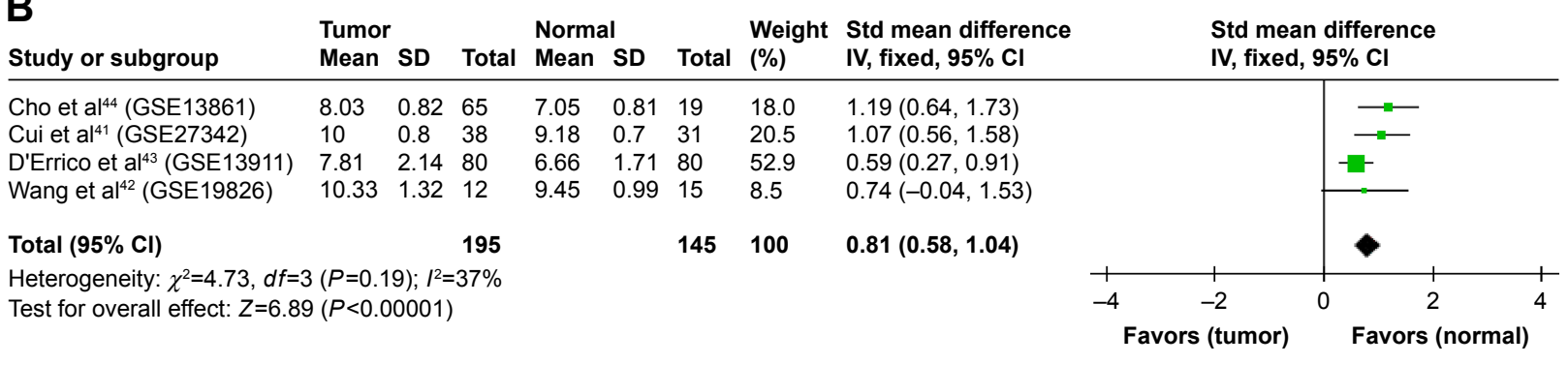

C

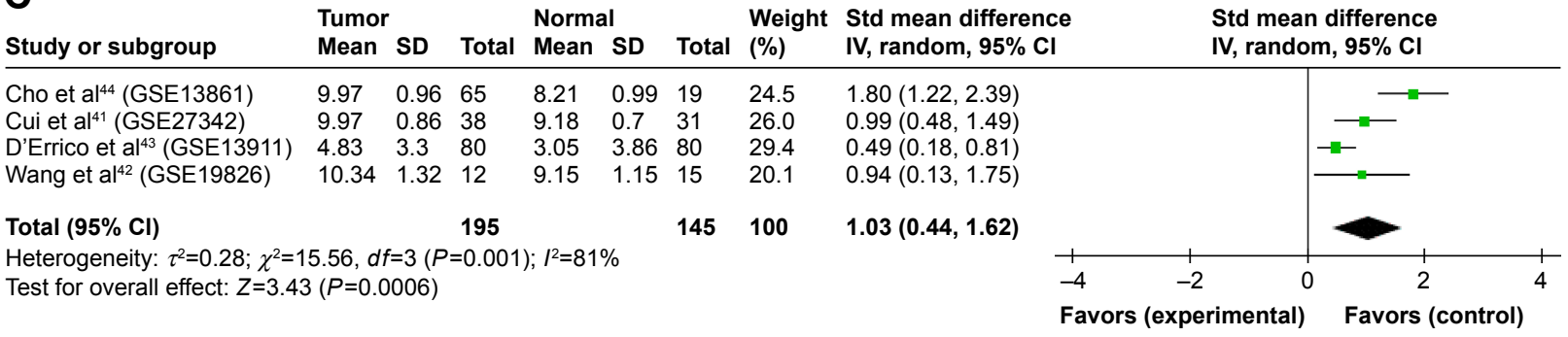

D

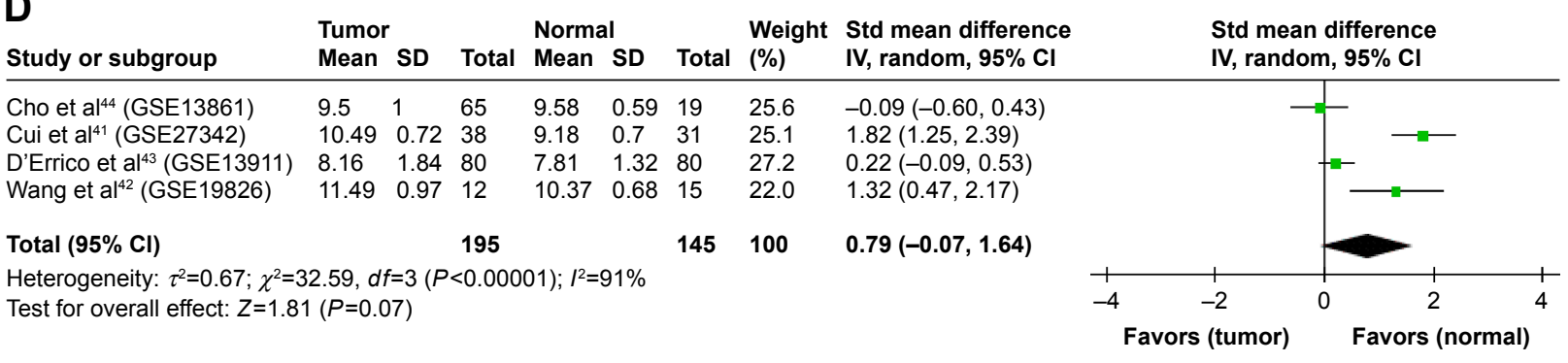

E

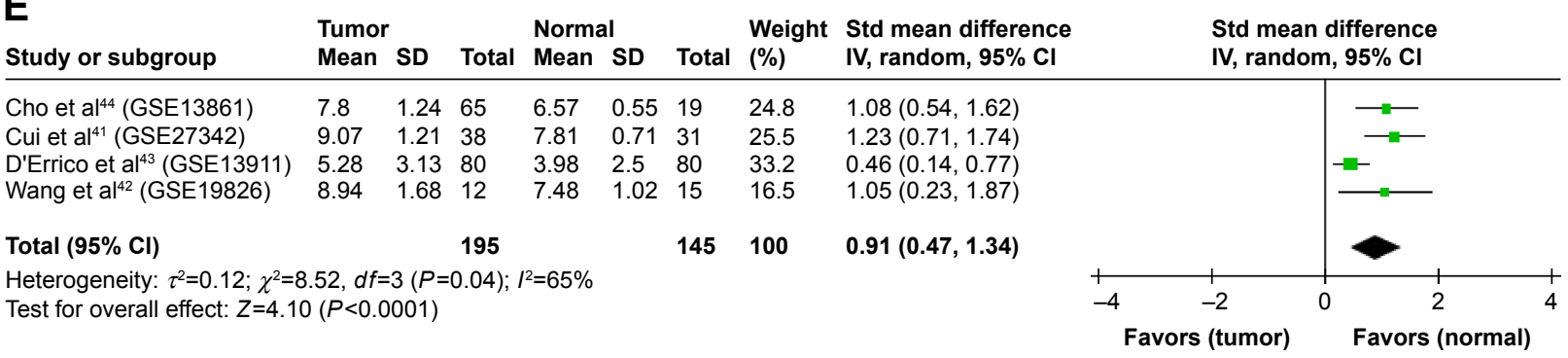

Figure I Cyclins expression in gastric cancer in Oncomine datasets.

Notes: (A) CCNA2, (B) CCNBI, (C) CCNB2, (D) CCND2, and (E) CCNEI. Data were analyzed in Oncomine datasets by comparative meta-analysis.

Abbreviations: GC, gastric cancer; std, standard.

(HR=1.36, 95\% CI: 1.09-1.68, $P=0.0055), \mathrm{CCNB} 1(\mathrm{HR}=1.34$, 95\% CI: $1.10-1.63, P=0.0034), \mathrm{CCNB} 2(\mathrm{HR}=1.47,95 \% \mathrm{CI}$ : 1.19-1.83, $P=0.00038)$, and CCNE1 $(\mathrm{HR}=1.40,95 \% \mathrm{CI}$ : $1.15-1.71, P=0.00093$ ) were related with poor OS (Figure 4).
The prognostic role of differentially expressed cyclins was reviewed in the previously published studies for validation (Table 2). Up to now, there are no data about the prognosis roles of CCNA2 and CCNB2. Three studies 

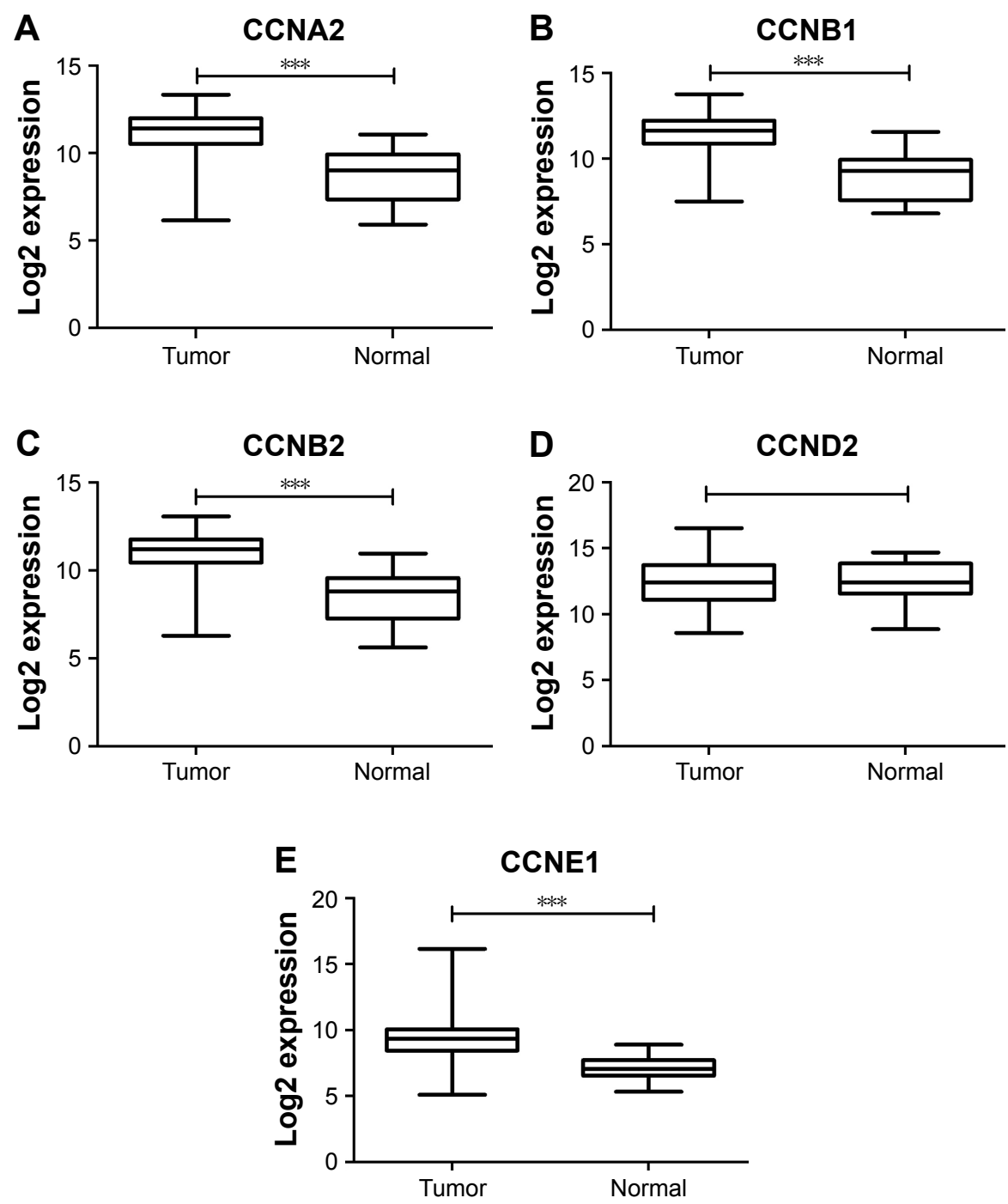

Figure 2 Cyclins expression in GC in TCGA dataset.

Notes: (A) CCNA2, (B) CCNBI, (C) CCNB2, (D) CCND2, and (E) CCNEI. Data were analyzed in TCGA dataset. $* * * P<0.001$.

Abbreviations: GC, gastric cancer; TCGA, The Cancer Genome Atlas.

evaluated the relationship between CCNB1 expression and clinicopathological features in GC. Three studies showed that CCNB1 high expression was related with lymph node metastasis. Two studies evaluated the prognosis role of CCNB1. The study from $\mathrm{Kim}^{53}$ did not indicate poor prognosis for CCNB1 overexpression GC patients. But Kim enrolled only 23 patients, and the results might not be reliable. The study involving 482 GC patients from Begnami et $\mathrm{al}^{35}$ showed poor 5-year OS for CCNB1 high-expression patients. Only one study evaluated the prognosis role of CCNE1. CCNE1 was associated with Lauren classification, tumor size, lymphatic and vascular invasion, but not with OS.

Then, further efforts were made to investigate the prognosis role of CCNB1 in GC. High expression of CCNB1 (HR $=2.63$, 95\% CI: $1.72-4.00, P=3.5 \mathrm{E}-06)$ predicted poor
OS in GC patients who received 5-FU-based chemotherapy treatment (Figure 5A). Furthermore, high expression of CCNE1 predicted poor OS in HER2-negative GC patients (HR $=1.42$, 95\% CI: $1.08-1.87, P=0.0117$; Figure 5B). The above results indicated that CCNE1 might be useful for guiding individualized treatments for GC patients.

\section{Enrichment analysis of cyclins}

The PPI network constructed is shown in Figure 6. In the PPI network, CDK1 and CDK2 were identified as PPI hub proteins. Several biological pathways were involved, including cell cycle, p53 signaling pathway, FoxO signaling pathway, viral carcinogenesis, and AMPK signaling pathway. Enrichment analysis also showed that cyclins were related with some TFs, such as FOXM1, SIN3A, NFYA, and E2F4 (Table 3). 
A

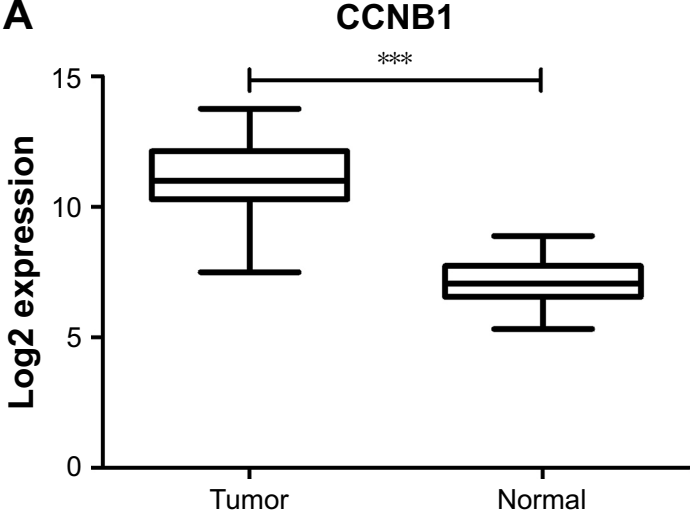

C

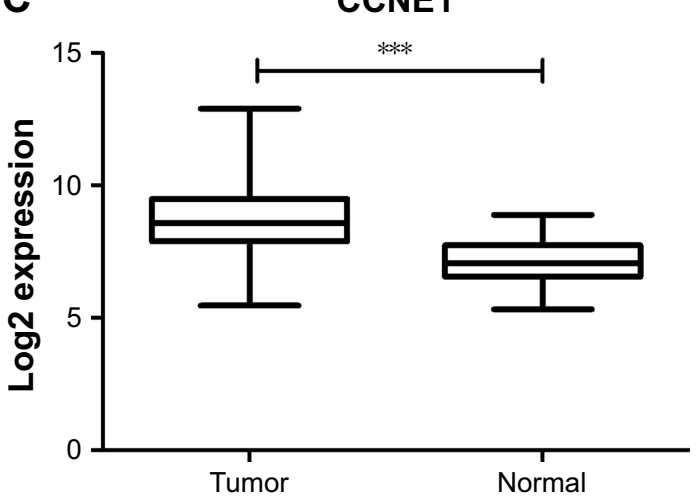

B

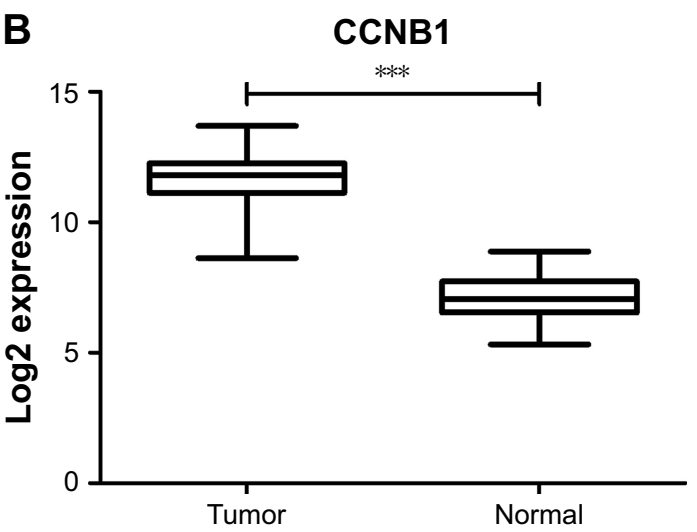

D

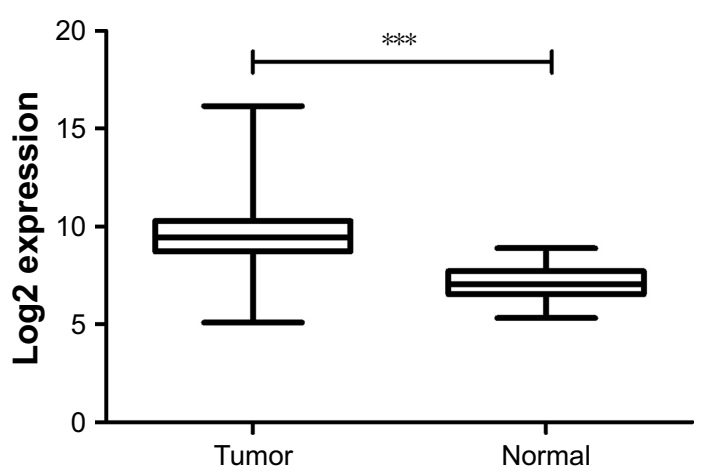

Figure $3 \mathrm{CCNBI}$ and CCNEI expressions in GC Lauren subtype.

Notes: (A) CCNBI expression in diffuse gastric adenocarcinoma. (B) CCNBI expression in gastric intestinal type adenocarcinoma. (C) CCNEI expression in diffuse gastric adenocarcinoma. (D) CCNEI expression in gastric intestinal type adenocarcinoma. Data were analyzed in TCGA dataset. $* * * P<0.001$.

Abbreviations: GC, gastric cancer; TCGA, The Cancer Genome Atlas.

\section{Discussion}

Publicly available microarray data have vast potential to serve as a source of biomarker discovery because there is enormous quantity of existing gene expression data. ${ }^{45,46}$ Potential roles for biomarkers include early diagnosis of disease, disease classification, prediction of prognosis model, and response to drug target therapy. ${ }^{47,48}$ Identification of genes associated with clinical survival rate and target therapy might provide a novel insight into GC pathogenesis and guide individualized treatments. In our study, the expression and prognosis roles of cyclins expressions were analyzed, and biological function was evaluated by enrichment analysis. Our study showed that high expression of cyclins mRNA was related with GC prognosis.

CCNA2 is overexpressed in several human cancers and correlated with tumor progression and shorter survival in lung, breast, and colorectal cancer. ${ }^{12,18,49-51}$ Our study showed that CCNA2 overexpression was an indicator of poor prognosis. Up to now, there is no study evaluating the expression and prognostic role of CCNA2 in GC patients. More efforts are needed to confirm expression pattern and prognostic role of CCNA2 in GC patients.

CCNB1 and CCNB2, which are key regulators of progression through the G2/M transition during the cell cycle, played significant roles in the progression and development of human cancers. ${ }^{13-15,19-24,35}$ In this report, CCNB1 and CCNB2 were upregulated in GC, which was consistent with previous studies. ${ }^{35,52-54}$ The CCNB1 mRNA overexpression was also confirmed in different GC Lauren subtypes, which indicated that CCNB1 might be helpful to guide GC classification. Relevant research showed that overexpression of CCNB1 was associated with clinical stage, ${ }^{54}$ lymph lode metastasis, ${ }^{35,53,54}$ and poor survival in GC patients. ${ }^{35}$ However, there are no data evaluating the prognostic role of CCNB2 in $\mathrm{GC}$ patients. In our study, high expression of CCNB1 and CCNB2 mRNAs predicted poor OS in GC patients through KM Plotter database analysis. ISL1, which could promote cell proliferation, is a novel regulator of the CCNB1 and CCNB2 genes. ${ }^{55}$ Downregulation of CCNB1 expression contributes to oridonin-induced cell cycle arrest at $\mathrm{G} 2 / \mathrm{M}$ phase and growth inhibition in SGC-7901 GC cells. ${ }^{56}$ Inhibition of 
A

213226_at (CCNA2)

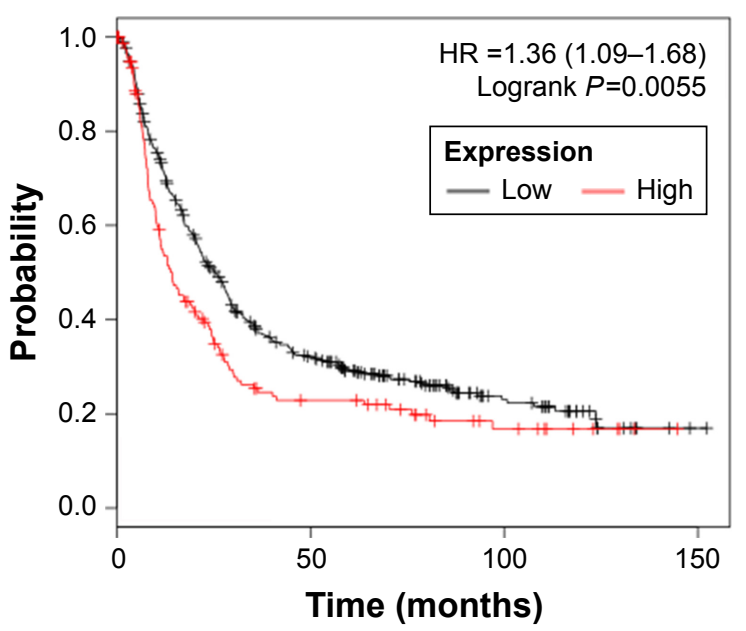

Number at risk

\begin{tabular}{|c|c|}
\hline Low 436 & 114 \\
\hline High 157 & 26 \\
\hline
\end{tabular}

C

202705_at (CCNB2)

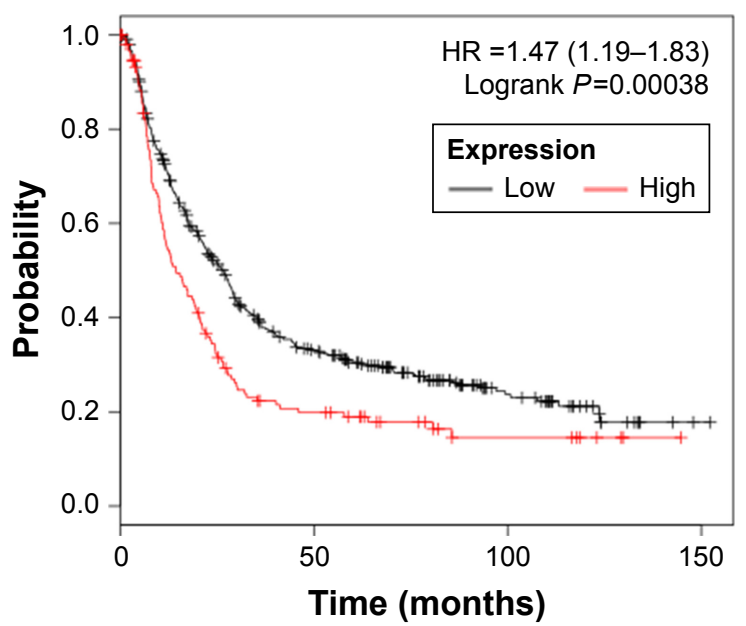

Number at risk

Low 442

High 151

116

24

34
7

7
B

214710_s_at (CCNB1)

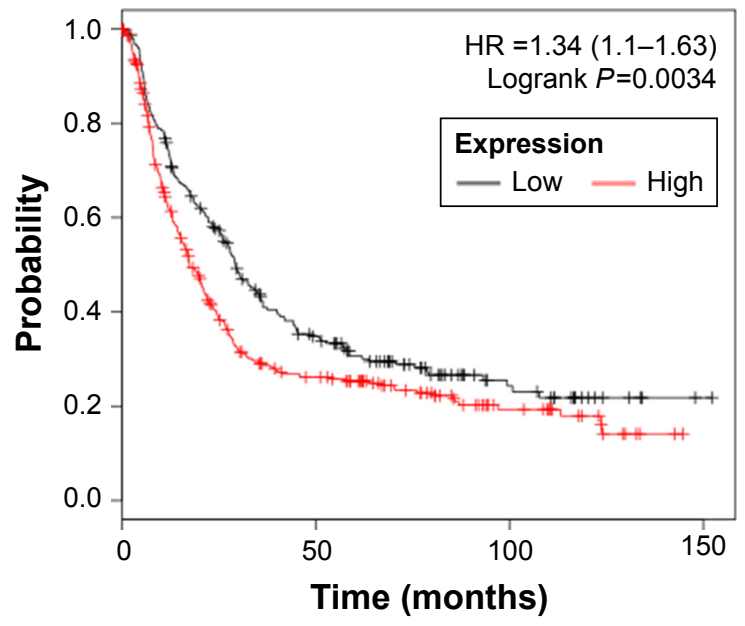

\section{Number at risk}

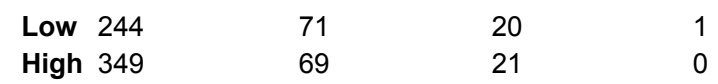

\section{213523_at (CCNE1)}

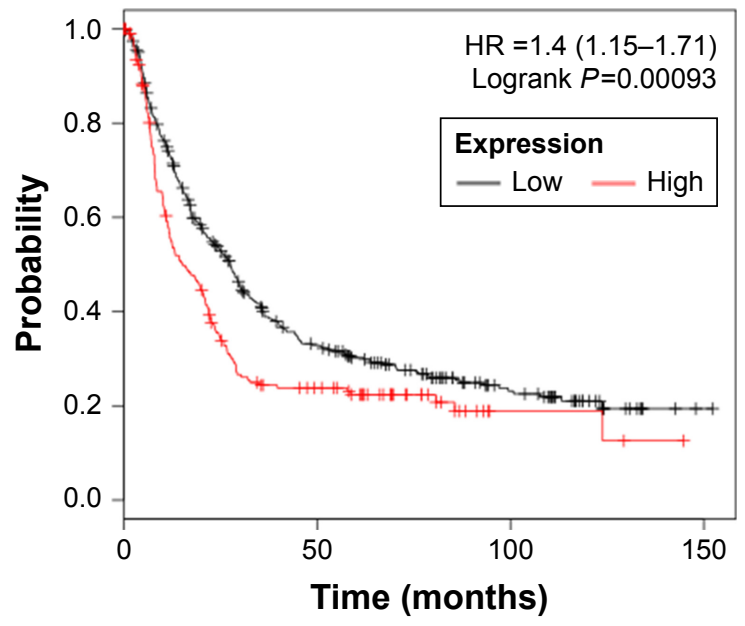

\section{Number at risk}

Low 388

High 205

$\begin{array}{lll}103 & 38 & 1 \\ 37 & 3 & 0\end{array}$

Figure 4 Prognosis roles of differentially expressed cyclins in GC patients in KM Plotter datasets.

Notes: (A) CCNA2, (B) CCNBI, (C) CCNB2, and (D) CCNEI. Data were analyzed in KM Plotter datasets.

Abbreviations: GC, gastric cancer; KM Plotter, Kaplan-Meier Plotter.

Table 2 The relationship between differentially expressed cyclins and clinicopathological features in previously published studies

\begin{tabular}{lll}
\hline & CCNB I & CCNE I \\
\hline Differentiation & $(54)^{*}$ & NA \\
Lauren classification & $(35)^{*}$ & $(37)^{*}$ \\
Tumor size & $\mathrm{NA}$ & $(37)^{*}$ \\
Stage & $(54)^{*}$ & $\mathrm{NA}$ \\
Lymphatic invasion & $(54)^{*}$ & $(37)^{*}$ \\
Lymph node metastasis & $(35,53,54)^{*}$ & $\mathrm{NA}$ \\
Vascular invasion & $\mathrm{NS}(54)$ & $(37)^{*}$ \\
Overall survival & $(35)^{*}, \mathrm{NS}(53)$ & $\mathrm{NS}(37)$ \\
\hline
\end{tabular}

Note: $* P<0.05$.

Abbreviations: NA, not available; NS, not significant.
GC cell growth by CCNB1 and CCNB2 may explain poor prognosis in GC patients.

The expression pattern of CCND2 presented conflicting results in GC. Some studies demonstrated that absence of CCND2 expression is associated with promoter hypermethylation in $\mathrm{GC},{ }^{57}$ as well as in breast, lung, prostate, and liver cancers. ${ }^{58-62}$ But some studies showed that CCND2 mRNA is overexpressed in GC..$^{36,63-65}$ Therefore, more studies are needed to evaluate the expression of CCND2 in GC to resolve the conflicting picture. In this report, there was no difference of CCND2 expression between GC and normal tissues. 
A

214710_s_at

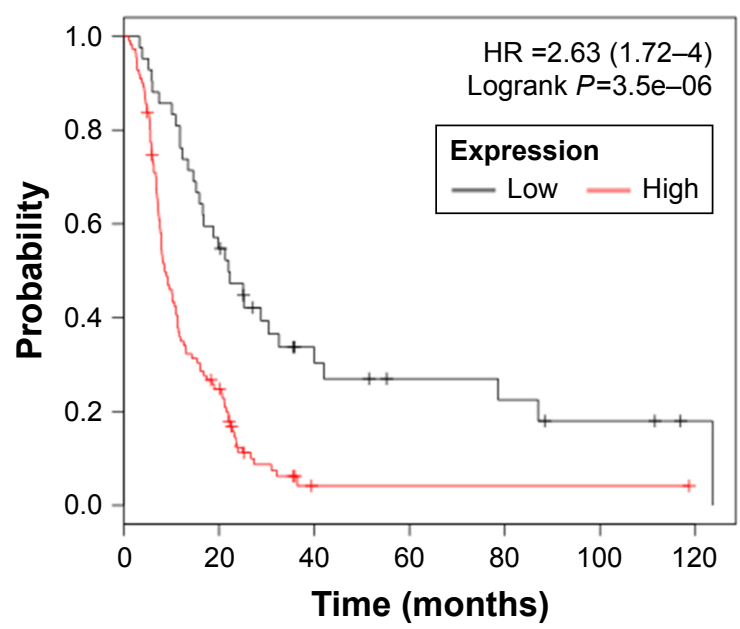

Number at risk

\begin{tabular}{|c|c|c|c|c|c|}
\hline Low 42 & 23 & 10 & 6 & 5 & 3 \\
\hline High 111 & 26 & 1 & 1 & 1 & 1 \\
\hline
\end{tabular}

B

214710_s_at

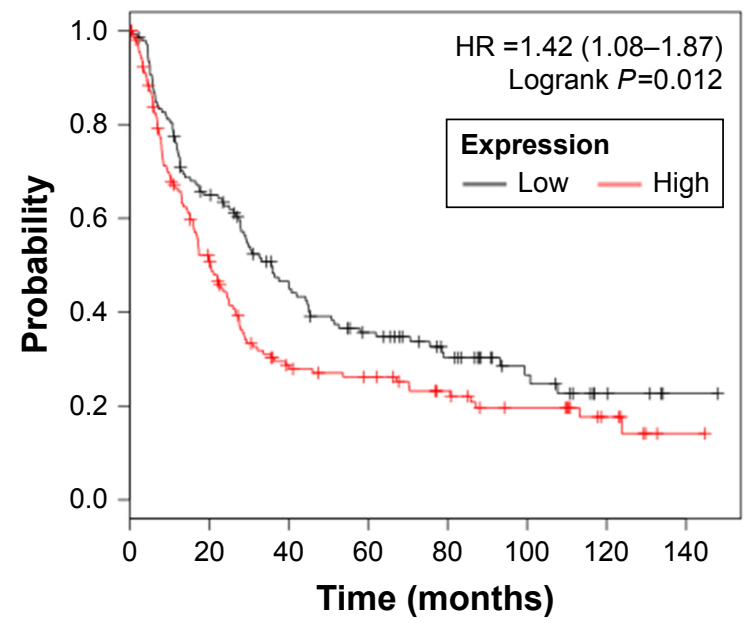

Number at risk

$\begin{array}{lllllllll}\text { Low } & 139 & 86 & 56 & 39 & 26 & 14 & 5 & 1\end{array}$

Figure 5 Prognosis roles of CCNBI in different GC patients.

Notes: (A) Prognostic role of CCNEI in GC patients who received 5-FU-based chemotherapy treatment. (B) Prognostic role of CCNEI in GC HER2-negative patients. Data were analyzed in KM Plotter datasets.

Abbreviations: GC, gastric cancer; KM Plotter, Kaplan-Meier Plotter.

Relevant research showed overexpression of CCND2 was related with better differentiation, lymph node metastasis, and poor survival, which were confirmed in GC by immunohistochemistry analysis. ${ }^{64,65}$ Another research showed that high expression of CCND2 mRNA was related with depth of invasion, lymph node metastasis, distant metastasis, and TNM stage and predicted poor prognosis in GC patients. ${ }^{36}$ But the samples involved in the above studies that evaluated

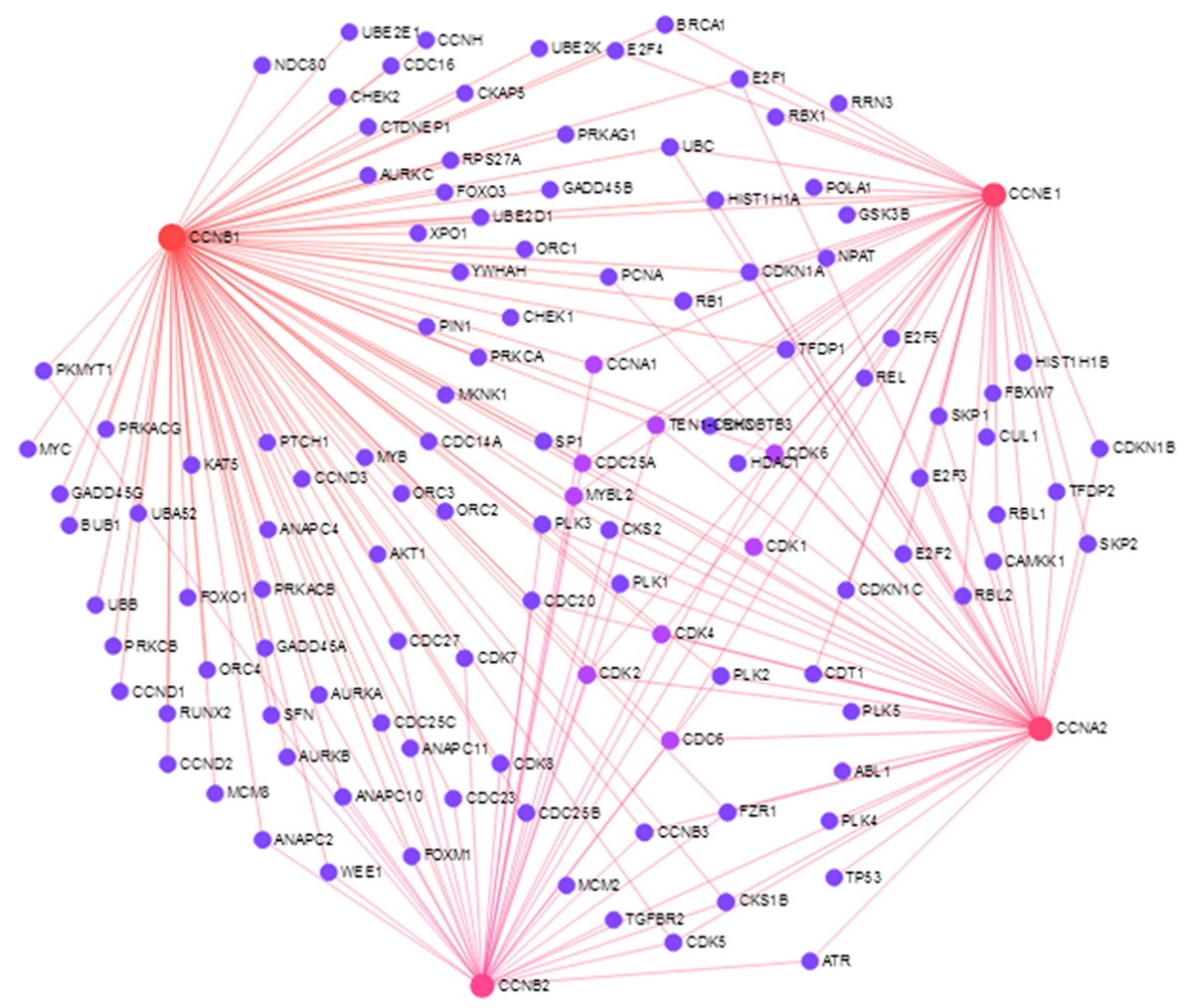

Figure 6 Protein-protein interaction network of differentially expressed cyclins. 
Table 3 Enrichment analysis of cyclins

\begin{tabular}{|c|c|c|c|}
\hline & $P$-value & Z-score & Genes involved \\
\hline \multicolumn{4}{|l|}{ KEGG pathway } \\
\hline Cell cycle & $2.252 \mathrm{E}-08$ & -1.733198 & CCNA2;CCNB2;CCNBI;CCNEI \\
\hline p53 signaling pathway & $1.255 \mathrm{E}-06$ & -1.737387 & CCNB2;CCNBI;CCNEI \\
\hline FoxO signaling pathway & 0.0008354 & -1.724599 & CCNB2;CCNBI \\
\hline Viral carcinogenesis & 0.0014146 & $-1.8297 \mid 4$ & CCNA2;CCNEI \\
\hline AMPK signaling pathway & 0.0391648 & -1.561928 & CCNA2 \\
\hline \multicolumn{4}{|l|}{ Transcription factors } \\
\hline FOXMI & 8.277E-06 & -1.918853 & CCNA2;CCNB2;CCNBI \\
\hline SIN3A & 0.0069103 & -1.730395 & CCNA2;CCNB2;CCNBI \\
\hline NFYA & 0.0347278 & -1.662154 & CCNA2;CCNB2;CCNBI \\
\hline E2F4 & 0.0359975 & -1.660036 & CCNA2;CCNEI \\
\hline
\end{tabular}

the prognostic role of CCND2 were small. Therefore, more studies are needed to evaluate the expression and prognostic role of CCND2 in GC.

CCNE1 is considered to be involved in the oncogenic process. ${ }^{9,66}$ CCNE1 overexpressions are significantly correlated with unfavorable prognosis in lung and breast cancers..$^{25-27,31-34}$ Relevant research demonstrated that CCNE1 in both mRNA and protein levels was associated with intestinal Lauren classification. ${ }^{37}$ In our study, CCNE1 was upregulated and predicted poor prognosis for GC patients. Recent evidence showed that CCNE1 was the target gene of microRNA-25, and cell apoptosis was observed when microRNA-25 and CCNE1 expressions downregulated, ${ }^{67}$ which might explain poor prognosis in GC patients with high CCNE1 mRNA expression.

HER 2 is a $185-\mathrm{kDa}$ protein, encoded by a gene located on chromosome 17q21. HER2 overexpression was detected in 6\%-23\% of GC patients. ${ }^{68,69}$ HER2-targeted therapies, using trastuzumab in addition to chemotherapy, showed significant benefit for patients with advanced GC. ${ }^{70}$ In this study, high expression of CCNB1 predicted poor OS in HER2-negative GC patients, which indicated that CCNB1 might be useful for guiding individualized treatments for GC patients. 5-FU adjuvant therapy of GC significantly improves OS. ${ }^{71}$ In this study, we found that high expression of CCNB1 predicted poor OS in GC patients who receive 5-FU-based chemotherapy treatment. Therefore, CCNB1 might be a potential therapy target for GC patients who receive 5-FU-based chemotherapy treatment.

In order to gain further insight into the biological mechanism of cyclins, enrichment analysis was performed. Cell cycle and p53 signaling pathway were identified as the most significant pathways that were related with cyclins. Dysregulated cell cycle progression is an important biological event during cancer pathogenesis. Present evidences have indicated that cyclins, CDKs, E2Fs, and p53 play an important role in cell cycle regulation. ${ }^{8}$ The above cell cycle regulators were the target molecules of most oncogenes. Recent studies showed that several molecules could inhibit cell proliferation and induce cell cycle arrest at $\mathrm{G} 2 / \mathrm{M}$ phase in GC cell lines, with downregulation of CDK1 and CCNB1 expressions but upregulation of p21 Waf1/Cip1, p27 Kip1, and p53 expressions. ${ }^{72-74}$ Another study showed that SPPHinduced S-phase arrest was mediated by upregulating the expression of E2F1 and downregulating those of CCNE1, CDK2, and CCNA2. ${ }^{75}$ FOXM1 was identified as the most significant TF through Enrich R platform. FOXM1 has been shown to regulate transcription of cell cycle genes, including Cdc25B, CDK1, cyclin B, and p27 Kip. ${ }^{76,77}$ Knockdown of FOXM1 resulted in enhanced cell growth inhibition in AGS cells. ${ }^{77}$ The above results provided a novel insight of cyclins into GC pathogenesis, which might be helpful for better understanding the biological mechanism of cyclins.

While the present study provides important insights into expression and prognostic roles of cyclins in GC patients at the mRNA level, it would be sensible to highlight the strengths and limitations of our study. Firstly, the publicly available databases were employed to analyze the expressions and prognostic roles of cyclins in GC patients. We pooled four datasets to evaluate the expressions of cyclins through Oncomine database. To evaluate the prognosis roles of cyclins, five GEO datasets were pooled to calculate the pooled HR. All the results of expression pattern and prognostic roles of cyclins were not based on a single dataset. Secondly, we analyzed the expressions of cyclins in TCGA dataset for validation. Also, the prognosis roles of cyclins were reviewed by comprehensive literature search. However, we did not perform polymerase chain reaction (PCR) or immunohistochemical to validate our findings. Though we 
performed an enrichment analysis, there are no experimental data about the mechanism of how cyclins affect the prognosis of GC patients, and additional efforts are needed to explore the biological roles of cyclins during GC pathogenesis.

\section{Conclusion}

In summary, CCNA2, CCNB1, CCNB2, and CCNE1 mRNA expressions are significantly higher in GC than in normal tissues. Furthermore, CCNB1 and CCNE1 could be helpful to guide GC Lauren classification. High expression of CCNB1 mRNA predicted poor OS in GC patients who received 5-FUbased chemotherapy treatment. Besides, high expression of CCNB1 predicted poor OS in HER2-negative GC patients. Enrichment analysis showed that cyclins are related with several biological pathways and interacts with some certain TFs. The above information might be useful for better understanding the clinical and biological roles of cyclins mRNA and guiding individualized treatments for GC patients.

\section{Disclosure}

The authors report no conflicts of interest in this work.

\section{References}

1. Murray CJ, Vos T, Lozano R, et al. Disability-adjusted life years (DALYs) for 291 diseases and injuries in 21 regions, 1990-2010: a systematic analysis for the Global Burden of Disease Study 2010. Lancet. 2012;380(9859):2197-2223.

2. Jemal A, Bray F, Center MM, Ferlay J, Ward E, Forman D. Global cancer statistics. CA Cancer J Clin. 2011;61(2):69-90.

3. Ferlay J, Shin HR, Bray F, et al. Estimates of worldwide burden of cancer in 2008: GLOBOCAN 2008. Int J Cancer. 2010;127(12):2893-2917.

4. Fitzmaurice C, Allen C, Barber RM, et al. Global, regional, and national cancer incidence, mortality, years of life lost, years lived with disability, and disability-adjusted life-years for 32 cancer groups, 1990 to 2015. JAMA Oncol. 2017;3(4):524-548.

5. Japanese Gastric Cancer Association. Japanese gastric cancer treatment guidelines 2014 (ver. 4). Gastric Cancer. 2017;20(1):1-19.

6. D'Angelica M, Gonen M, Brennan MF, Turnbull AD, Bains M, Karpeh MS. Patterns of initial recurrence in completely resected gastric adenocarcinoma. Ann Surg. 2004;240(5):808-816.

7. Yoo CH, Noh SH, Shin DW, Choi SH, Min JS. Recurrence following curative resection for gastric carcinoma. Br J Surg. 2000;87(2):236-242.

8. Wiman KG, Zhivotovsky B. Understanding cell cycle and cell death regulation provides novel weapons against human diseases. $J$ Intern Med. 2017;281(5):483-495.

9. Stamatakos M, Palla V, Karaiskos I, et al. Cell cyclins: triggering elements of cancer or not? World J Surg Oncol. 2010;8:111.

10. von Bergwelt-Baildon MS, Kondo E, Klein-González N, Wendtner CM. The cyclins: a family of widely expressed tumor antigens? Expert Rev Vaccines. 2011;10(3):389-395.

11. Muşat M, Morris DG, Korbonits M, Grossman AB. Cyclins and their related proteins in pituitary tumourigenesis. Mol Cell Endocrinol. 2010;326(1-2):25-29.

12. Ko E, Kim Y, Cho EY, et al. Synergistic effect of Bcl-2 and cyclin A2 on adverse recurrence-free survival in stage I non-small cell lung cancer. Ann Surg Oncol. 2013;20(3):1005-1012.

13. Cooper WA, Kohonen-Corish MR, Mccaughan B, Kennedy C, Sutherland RL, Lee CS. Expression and prognostic significance of cyclin B1 and cyclin A in non-small cell lung cancer. Histopathology. 2009;55(1):28-36.
14. Takashima S, Saito H, Takahashi N, et al. Strong expression of cyclin B2 mRNA correlates with a poor prognosis in patients with non-small cell lung cancer. Tumour Biol. 2014;35(5):4257-4265.

15. Qian X, Song X, He Y, et al. CCNB2 overexpression is a poor prognostic biomarker in Chinese NSCLC patients. Biomed Pharmacother. 2015;74:222-227.

16. Lee E, Jin D, Lee BB, et al. Negative effect of cyclin D1 overexpression on recurrence-free survival in stage II-IIIA lung adenocarcinoma and its expression modulation by vorinostat in vitro. BMC Cancer. 2015; 15:982.

17. Xu P, Zhao M, Liu Z, et al. Elevated nuclear CCND1 expression confers an unfavorable prognosis for early stage lung adenocarcinoma patients. Int J Clin Exp Pathol. 2015;8(12):15887-15894.

18. Gao T, Han Y, Yu L, Ao S, Li Z, Ji J. CCNA2 is a prognostic biomarker for ER+ breast cancer and tamoxifen resistance. PLoS One. 2014; 9(3): 91771.

19. Agarwal R, Gonzalez-Angulo AM, Myhre S, et al. Integrative analysis of cyclin protein levels identifies cyclin b1 as a classifier and predictor of outcomes in breast cancer. Clin Cancer Res. 2009;15(11):3654-3662.

20. Koliadi A, Nilsson C, Holmqvist M, et al. Cyclin B is an immunohistochemical proliferation marker which can predict for breast cancer death in low-risk node negative breast cancer. Acta Oncol. 2010;49(6): 816-820.

21. Aaltonen K, Amini RM, Heikkilä P, et al. High cyclin B1 expression is associated with poor survival in breast cancer. Br J Cancer. 2009; 100(7):1055-1060.

22. Ding $\mathrm{K}$, Li W, Zou Z, Zou X, Wang C. CCNB1 is a prognostic biomarker for ER+ breast cancer. Med Hypotheses. 2014;83(3):359-364.

23. Niméus-Malmström E, Koliadi A, Ahlin C, et al. Cyclin B1 is a prognostic proliferation marker with a high reproducibility in a populationbased lymph node negative breast cancer cohort. Int J Cancer. 2010; 127(4):961-967.

24. Shubbar E, Kovács A, Hajizadeh S, et al. Elevated cyclin B2 expression in invasive breast carcinoma is associated with unfavorable clinical outcome. BMC Cancer. 2013;13:1.

25. Alexander A, Karakas C, Chen X, et al. Cyclin E overexpression as a biomarker for combination treatment strategies in inflammatory breast cancer. Oncotarget. 2017;8(9):14897-14911.

26. Lundgren C, Ahlin C, Holmberg L, Amini RM, Fjällskog ML, Blomqvist C. Cyclin E1 is a strong prognostic marker for death from lymph node negative breast cancer. A population-based case-control study. Acta Oncol. 2015;54(4):538-544.

27. Luhtala S, Staff S, Tanner M, Isola J. Cyclin E amplification, overexpression, and relapse-free survival in HER-2-positive primary breast cancer. Tumour Biol. 2016;37(7):9813-9823.

28. Caldon CE, Sergio CM, Kang J, et al. Cyclin E2 overexpression is associated with endocrine resistance but not insensitivity to CDK2 inhibition in human breast cancer cells. Mol Cancer Ther. 2012;11(7): $1488-1499$.

29. Hashimoto T, Yanaihara N, Okamoto A, et al. Cyclin D1 predicts the prognosis of advanced serous ovarian cancer. Exp Ther Med. 2011;2(2): 213-219.

30. Wang H, Wang H, Makki MS, et al. Overexpression of $\beta$-catenin and cyclin D1 predicts a poor prognosis in ovarian serous carcinomas. Int J Clin Exp Pathol. 2014;7(1):264-271.

31. Ayhan A, Kuhn E, Wu RC, et al. CCNE1 copy-number gain and overexpression identify ovarian clear cell carcinoma with a poor prognosis. Mod Pathol. 2017;30(2):297-303.

32. Pils D, Bachmayr-Heyda A, Auer K, et al. Cyclin E1 (CCNE1) as independent positive prognostic factor in advanced stage serous ovarian cancer patients - a study of the OVCAD consortium. Eur J Cancer. 2014;50(1):99-110.

33. Nakayama N, Nakayama K, Shamima Y, et al. Gene amplification CCNE1 is related to poor survival and potential therapeutic target in ovarian cancer. Cancer. 2010;116(11):2621-2634.

34. Kanska J, Zakhour M, Taylor-Harding B, Karlan BY, Wiedemeyer WR. Cyclin $\mathrm{E}$ as a potential therapeutic target in high grade serous ovarian cancer. Gynecol Oncol. 2016;143(1):152-158. 
35. Begnami MD, Fregnani JH, Nonogaki S, Soares FA. Evaluation of cell cycle protein expression in gastric cancer: cyclin B1 expression and its prognostic implication. Hum Pathol. 2010;41(8):1120-1127.

36. Shi H, Han J, Yue S, Zhang T, Zhu W, Zhang D. Prognostic significance of combined microRNA-206 and Cyclin D2 in gastric cancer patients after curative surgery: a retrospective cohort study. Biomed Pharmacother. 2015;71:210-215.

37. Kouraklis G, Katsoulis IE, Theocharis S, et al. Does the expression of cyclin E, pRb, and p21 correlate with prognosis in gastric adenocarcinoma? Dig Dis Sci. 2009;54(5):1015-1020.

38. Rhodes DR, Kalyana-Sundaram S, Mahavisno V, et al. Oncomine 3.0: genes, pathways, and networks in a collection of 18,000 cancer gene expression profiles. Neoplasia. 2007;9(2):166-180.

39. Szász AM, Lánczky A, Nagy Á, et al. Cross-validation of survival associated biomarkers in gastric cancer using transcriptomic data of 1,065 patients. Oncotarget. 2016;7(31):49322-49333.

40. Kuleshov MV, Jones MR, Rouillard AD, et al. Enrichr: a comprehensive gene set enrichment analysis web server 2016 update. Nucleic Acids Res. 2016;44(W1):W90-W97.

41. Cui J, Chen Y, Chou WC, et al. An integrated transcriptomic and computational analysis for biomarker identification in gastric cancer. Nucleic Acids Res. 2011;39(4):1197-1207.

42. Wang Q, Wen YG, Li DP, et al. Upregulated INHBA expression is associated with poor survival in gastric cancer. Med Oncol. 2012;29(1): 77-83.

43. D’Errico M, de Rinaldis E, Blasi MF, et al. Genome-wide expression profile of sporadic gastric cancers with microsatellite instability. Eur $J$ Cancer. 2009;45(3):461-469.

44. Cho JY, Lim JY, Cheong JH, et al. Gene expression signature-based prognostic risk score in gastric cancer. Clin Cancer Res. 2011;17(7): 1850-1857.

45. Rudy J, Valafar F. Empirical comparison of cross-platform normalization methods for gene expression data. BMC Bioinformatics. 2011 $12: 467$.

46. Rung J, Brazma A. Reuse of public genome-wide gene expression data. Nat Rev Genet. 2013;14(2):89-99.

47. Slonim DK, Yanai I. Getting started in gene expression microarray analysis. PLoS Comput Biol. 2009;5(10):e1000543.

48. Pepe MS, Feng Z. Improving biomarker identification with better designs and reporting. Clin Chem. 2011;57(8):1093-1095.

49. Ohashi R, Gao C, Miyazaki M, et al. Enhanced expression of cyclin E and cyclin A in human hepatocellular carcinomas. Anticancer Res. 2001; 21(1B):657-662

50. Renshaw AA, Loughlin KR, Dutta A. Cyclin A and MIB1 (Ki67) as markers of proliferative activity in primary renal neoplasms. Mod Pathol. 1998;11(10):963-966.

51. Handa K, Yamakawa M, Takeda H, Kimura S, Takahashi T. Expression of cell cycle markers in colorectal carcinoma: superiority of cyclin A as an indicator of poor prognosis. Int J Cancer. 1999;84(3):225-233.

52. Wang DG, Chen G, Wen XY, Wang D, Cheng ZH, Sun SQ. Identification of biomarkers for diagnosis of gastric cancer by bioinformatics. Asian Pac J Cancer Prev. 2015;16(4):1361-1365.

53. Kim DH. Prognostic implications of cyclin B1, p34cdc2, p27(Kip1) and p53 expression in gastric cancer. Yonsei Med J. 2007;48(4):694-700.

54. Yasuda M, Takesue F, Inutsuka S, Honda M, Nozoe T, Korenaga D Overexpression of cyclin B1 in gastric cancer and its clinicopathological significance: an immunohistological study. J Cancer Res Clin Oncol. 2002;128(8):412-416.

55. Shi Q, Wang W, Jia Z, Chen P, Ma K, Zhou C. ISL1, a novel regulator of CCNB1, CCNB2 and c-MYC genes, promotes gastric cancer cell proliferation and tumor growth. Oncotarget. 2016;7(24):36489-36500.

56. Gao SY, Li J, Qu XY, Zhu N, Ji YB. Downregulation of Cdk1 and cyclinB1 expression contributes to oridonin-induced cell cycle arrest at G2/M phase and growth inhibition in SGC-7901 gastric cancer cells. Asian Pac J Cancer Prev. 2014;15(15):6437-6441.

57. Yu J, Leung WK, Ebert MP, et al. Absence of cyclin D2 expression is associated with promoter hypermethylation in gastric cancer. $\mathrm{Br} J$ Cancer. 2003;88(10):1560-1565.
58. Truong PK, Lao TD, Doan TP, Le TA. Loss of expression of cyclin d 2 by aberrant DNA methylation: a potential biomarker in vietnamese breast cancer patients. Asian Pac J Cancer Prev. 2015;16(6):2209-2213.

59. Evron E, Umbricht CB, Korz D, et al. Loss of cyclin D2 expression in the majority of breast cancers is associated with promoter hypermethylation. Cancer Res. 2001;61(6):2782-2787.

60. Salskov A, Hawes SE, Stern JE, et al. Hypermethylation of CCND2 may reflect a smoking-induced precancerous change in the lung. J Oncol. 2011;2011:950140-950149

61. Henrique R, Costa VL, Cerveira N, et al. Hypermethylation of cyclin D2 is associated with loss of mRNA expression and tumor development in prostate cancer. J Mol Med. 2006;84(11):911-918.

62. Tsutsui M, Iizuka N, Moribe T, et al. Methylated cyclin D2 gene circulating in the blood as a prognosis predictor of hepatocellular carcinoma. Clin Chim Acta. 2010;411(7-8):516-520.

63. Yu J, Miehlke S, Ebert MP, et al. Expression of cyclin genes in human gastric cancer and in first degree relatives. Chin Med J. 2002; 115(5):710-715.

64. Takano Y, Kato Y, van Diest PJ, Masuda M, Mitomi H, Okayasu I. Cyclin D2 overexpression and lack of p27 correlate positively and cyclin $\mathrm{E}$ inversely with a poor prognosis in gastric cancer cases. $\mathrm{Am} \mathrm{J}$ Pathol. 2000;156(2):585-594.

65. Takano Y, Kato Y, Masuda M, Ohshima Y, Okayasu I. Cyclin D2, but not cyclin D1, overexpression closely correlates with gastric cancer progression and prognosis. J Pathol. 1999;189(2):194-200.

66. Keyomarsi K, Herliczek TW. The role of cyclin E in cell proliferation, development and cancer. Prog Cell Cycle Res. 1997;3:171-191.

67. Zhang Y, Peng Z, Zhao Y, Chen L. microRNA-25 inhibits cell apoptosis of human gastric adenocarcinoma cell line AGS via regulating CCNE1 and MYC. Med Sci Monit. 2016;22:1415-1420.

68. Gravalos C, Jimeno A. HER2 in gastric cancer: a new prognostic factor and a novel therapeutic target. Ann Oncol. 2008;19(9):1523-1529.

69. Schoppmann SF, Jesch B, Zacherl J, et al. HER-2 status in primary oesophageal cancer, lymph nodes and distant metastases. Br J Surg. 2011;98(10):1408-1413.

70. Bang YJ, van Cutsem E, Feyereislova A, et al. Trastuzumab in combination with chemotherapy versus chemotherapy alone for treatment of HER2-positive advanced gastric or gastro-oesophageal junction cancer (ToGA): a phase 3, open-label, randomised controlled trial. Lancet. 2010;376(9742):687-697.

71. Jácome AA, Sankarankutty AK, dos Santos JS. Adjuvant therapy for gastric cancer: what have we learned since INT0116? World $J$ Gastroenterol. 2015;21(13):3850-3859.

72. Lee MH, Cho Y, Kim DH, et al. Menadione induces G2/M arrest in gastric cancer cells by down-regulation of $\mathrm{CDC} 25 \mathrm{C}$ and proteasome mediated degradation of CDK1 and cyclin B1. Am J Transl Res. 2015;8(12): 5246-5255.

73. Yuan CX, Zhou ZW, Yang YX, et al. Inhibition of mitotic Aurora kinase A by alisertib induces apoptosis and autophagy of human gastric cancer AGS and NCI-N78 cells. Drug Des Devel Ther. 2015;9:487-508.

74. Yuan CX, Zhou ZW, Yang YX, et al. Danusertib, a potent pan-Aurora kinase and ABL kinase inhibitor, induces cell cycle arrest and programmed cell death and inhibits epithelial to mesenchymal transition involving the $\mathrm{PI} 3 \mathrm{~K} / \mathrm{Akt} / \mathrm{mTOR}$-mediated signaling pathway in human gastric cancer AGS and NCI-N78 cells. Drug Des Devel Ther. 2015;9: 1293-1318.

75. Li X, Xie H, Chen Y, Lang M, Chen Y, Shi L. Silkworm pupa protein hydrolysate induces mitochondria-dependent apoptosis and $\mathrm{S}$ phase cell cycle arrest in human gastric cancer SGC-7901 cells. Int J Mol Sci. 2018;19(4):1013.

76. Zeng J, Wang L, Li Q, et al. FoxM1 is up-regulated in gastric cancer and its inhibition leads to cellular senescence, partially dependent on p27 kip1. J Pathol. 2009;218(4):419-427.

77. Xiang HL, Liu F, Quan MF, Cao JG, Lv Y. 7-Difluoromethoxyl-5,4'di-n-octylgenistein inhibits growth of gastric cancer cells through downregulating forkhead box M1. World J Gastroenterol. 2012;18(33): 4618-4626. 


\section{Supplementary materials}

A

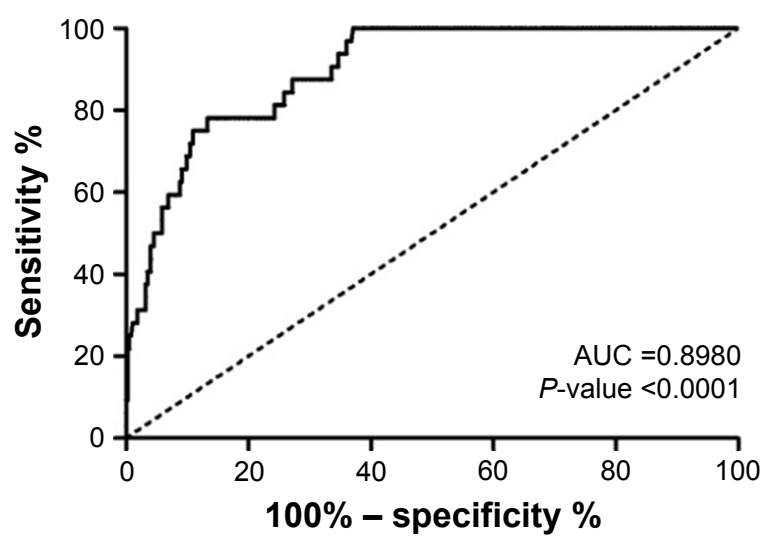

C

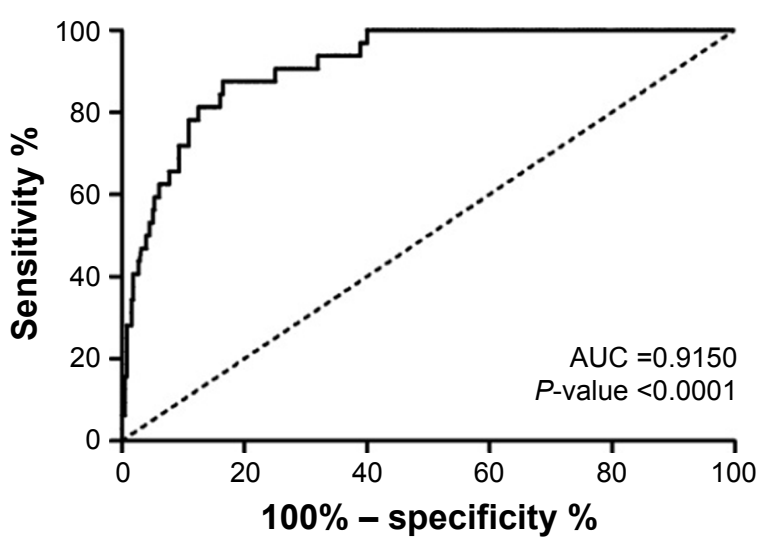

B

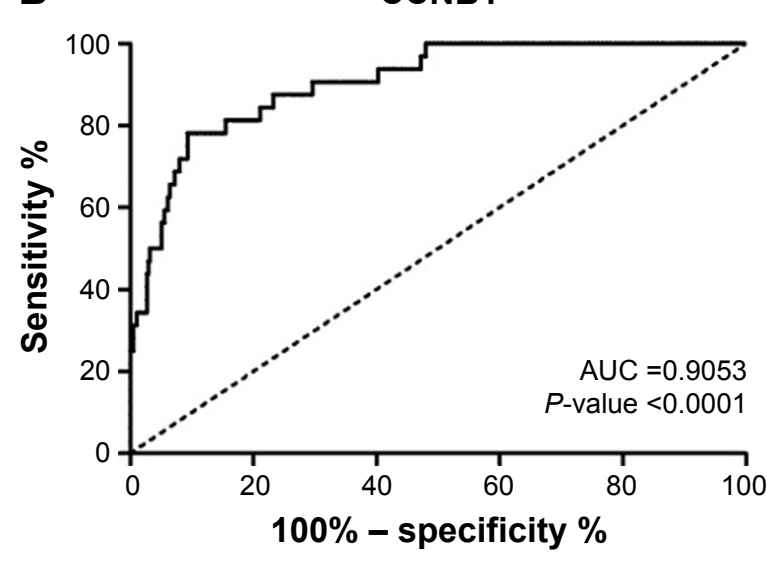

D

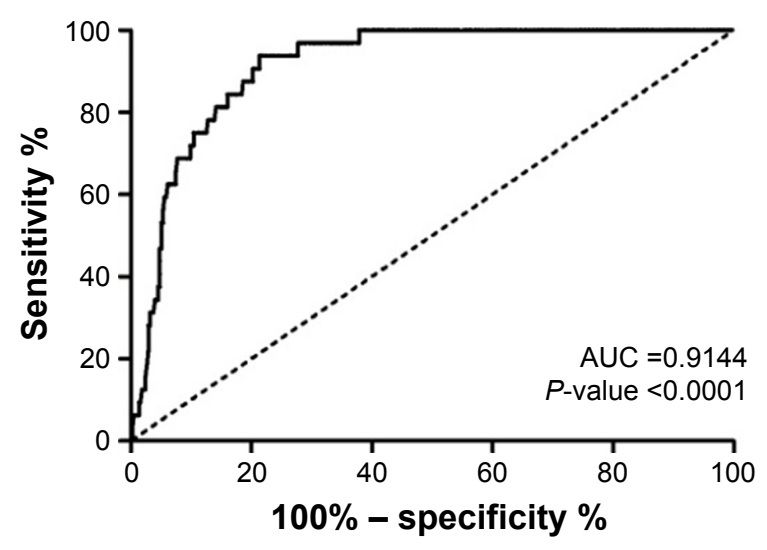

Figure SI The ROC curves of CCNA2, CCNBI, CCNB2, and CCNEI were constructed for GC diagnosis. Notes: (A) CCNA2, (B) CCNBI, (C) CCNB2, and (D) CCNEI.

Abbreviations: AUC, area under curve; GC, gastric cancer; ROC, receiver operating characteristic. 
A

CCNB1

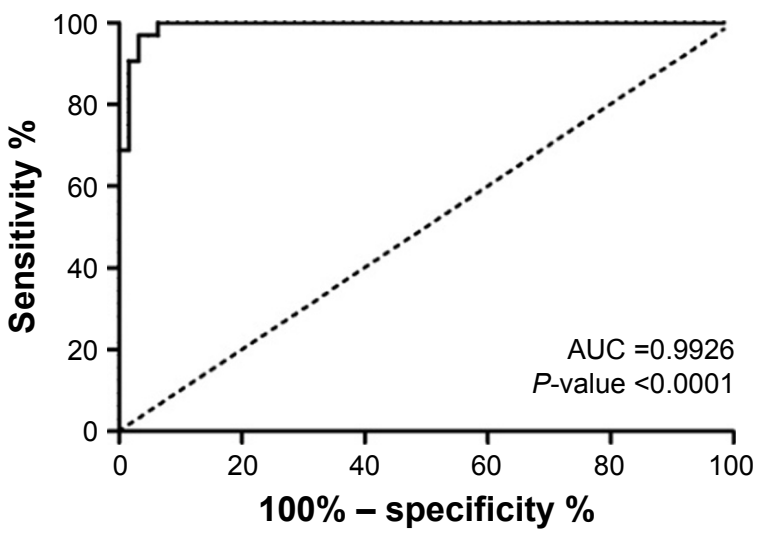

C

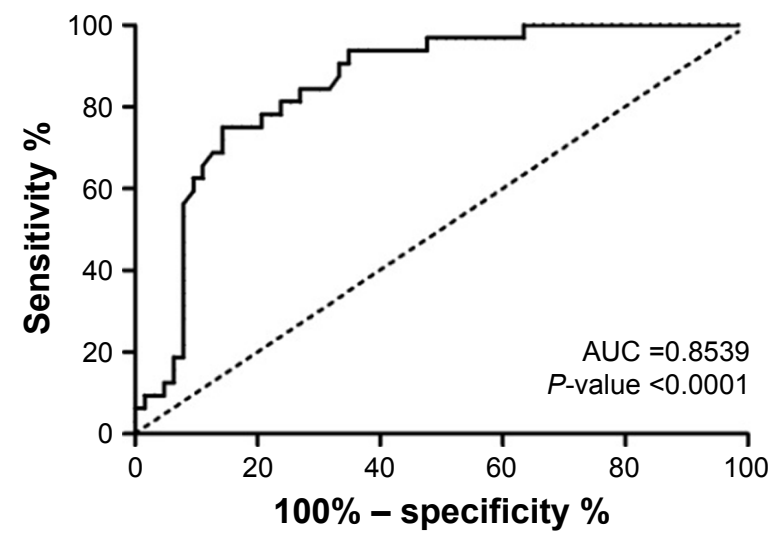

B $\quad$ CCNB1

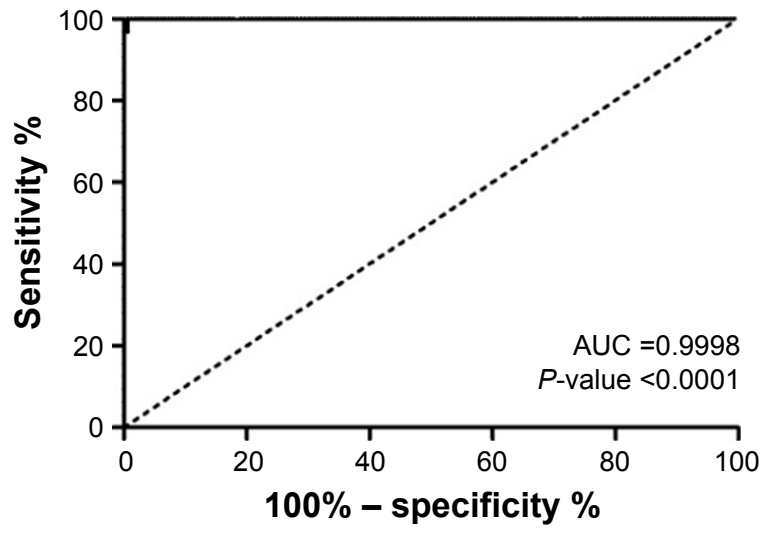

D $\quad$ CCNE1

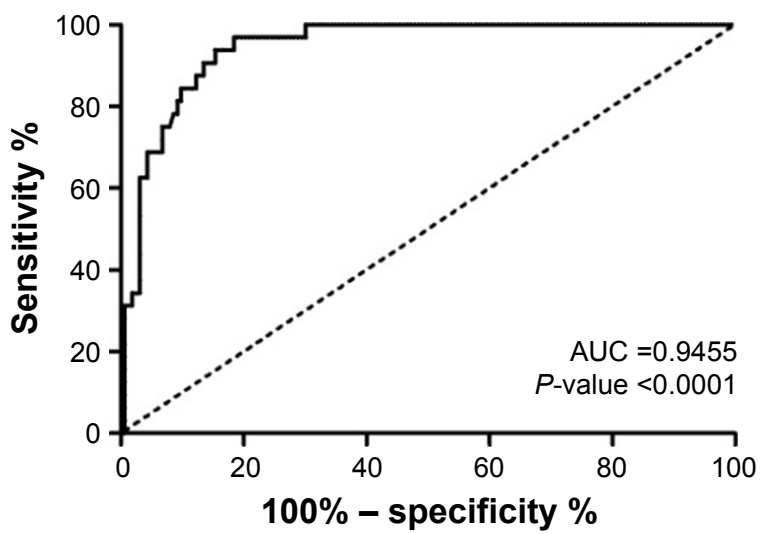

Figure S2 The ROC curves of CCNBI and CCNEI for GC Lauren subtype classification.

Notes: (A) CCNBI for diffuse gastric adenocarcinoma. (B) CCNBI gastric intestinal type adenocarcinoma. (C) CCNEI for diffuse gastric adenocarcinoma. (D) CCNEI gastric intestinal type adenocarcinoma.

Abbreviations: AUC, area under curve; GC, gastric cancer; ROC, receiver operating characteristic.

\section{Publish your work in this journal}

OncoTargets and Therapy is an international, peer-reviewed, open access journal focusing on the pathological basis of all cancers, potential targets for therapy and treatment protocols employed to improve the management of cancer patients. The journal also focuses on the impact of management programs and new therapeutic agents and protocols on patient perspectives such as quality of life, adherence and satisfaction. The manuscript management system is completely online and includes a very quick and fair peer-review system, which is all easy to use. Visit http://www.dovepress.com/testimonials.php to read real quotes from published authors. 